\title{
Correction to: Are Happier Nations More Responsible? Examining the Link Between Happiness and Sustainability
}

\author{
Yomna M. Sameer ${ }^{1}$ (D) . Suzanna Elmassah ${ }^{2,3} \cdot$ Charilaos Mertzanis $^{4}$. \\ Lujain El-Maghraby 5
}

Published online: 15 June 2021

(c) Springer Nature B.V. 2021

\section{Correction to: Social Indicators Research https://doi.org/10.1007/s11205-021-02698-4}

In the original publication of the article, the co-author Dr Lujain El-Maghraby affiliation was published incorrectly. Now the same has been provided in this correction.

Publisher's Note Springer Nature remains neutral with regard to jurisdictional claims in published maps and institutional affiliations.

The original article can be found online at https://doi.org/10.1007/s11205-021-02698-4.

Yomna M. Sameer

Yomna.morsy@adu.ac.ae

Suzanna Elmassah

Suzanna.elmassah@feps.edu.eg; Suzanna.elmassah@zu.ac.ae

Charilaos Mertzanis

charilaos.mertzanis@adu.ac.ae

Lujain El-Maghraby

Lujain.almaghraby@tkh.edu.eg

1 Strategy, Organization and Entrepreneurship Division, College of Business, Abu Dhabi University, Dubai, UAE

2 Department of Economics, Faculty of Economics and Political Science, Cairo University, Cairo, Egypt

3 Department of Finance, College of Business, Zayed University, Abu Dhabi, UAE

4 Department of Finance, College of Business, Abu Dhabi University, Dubai, UAE

5 Department of Business Administration, Coventry University Branch Campus at The Knowledge Hub Universities, New Administrative Capital, Cairo, Egypt 